\title{
Informing Clients in Education about Instructional Offerings and Careers in the ICT Industry
}

\author{
Nina Evans \\ Technikon Pretoria, South Africa
}

nevans@techpta.ac.za

\begin{abstract}
Organisations of the twenty first century are increasingly dependent on knowledge, information- and communication technology (ICT). Due to the changes in modern organisations, a new role and set of expectations have emerged for ICT workers. Academic institutions have a responsibility to determine the needs of the ICT industry and develop the necessary knowledge, skills and abilities in their learners, through relevant instructional offerings and course contents.
\end{abstract}

Companies in the ICT industry regard higher education institutions as important clients. On the other hand, the clientele for higher education institutions include the learners, the ICT industry and the public. This article suggests that higher education institutions should remain informed about the needs of the ICT industry and, at the same time, keep their learners and other clients informed about these needs, career- and training options in the ICT field. It is argued that the management of this "two-way" practical informing science process - to satisfy both stakeholders- is the responsibility of higher education institutions.

The questions that continually need to be answered through such an informing process are : To what extent has the ICT world changed and what is the influence of such changes on the demands made of ICT workers? Do these changing demands have an influence on the ICT training institutions and how should academic institutions adapt their courses accordingly? How should learners be kept informed of the changing industry needs and instructional offerings, enabling the $\mathrm{m}$ to make wiser career choices?

Keywords: Informing Science, Information Systems, Information and Communication Technology (ICT), Higher Education, Business Analysis, System Analysis, Relationship Management, Information Technology (IT)

\section{Introduction}

This paper describes a research process implemented at Technikon Pretoria in Gauteng (South Africa), to bridge the gap between the training we provide to Information Technology (IT) learners and the needs of the Information and Communication Technology (ICT) industry - the major employers of our learners. The article describes the research process from its initiation in 1999 up to current ongoing research projects.

Material published as part of these proceedings, either on-line or in print, is copyrighted by Informing Science. Permission to make digital or paper copy of part or all of these works for personal or classroom use is granted without fee provided that the copies are not made or distributed for profit or commercial advantage AND that copies 1) bear this notice in full and 2) give the full citation on the first page. It is permissible to abstract these works so long as credit is given. To copy in all other cases or to republish or to post on a server or to redistribute to lists requires specific permission from the publisher at Publisher@InformingScience.org
The Department of Computer Technology completed a research project in 2001 to determine the needs of the industry in our region and to make the necessary changes to our instructional offerings. The research resulted in a new set of instructional offerings focusing on various specialisation areas of the ICT field. A Faculty of ICT was then created, consisting of a number of departments, each responsible for training and edu- 
cation in one or two main focus areas. Follow-up research was initiated by the department of Business Applications and IT Management during 2002, to investigate the career of the business and systems analyst and to determine what is expected of our learners. This department is responsible for producing employees with strong business-, IT- and interpersonal skills who can play a relationship management role towards bridging the gap between business and IT (referred to as the "expectation gap", "adverse business-IT relationship" or "the lack of business-IT strategic alignment" in various literature sources). The focus of this research effort is to determine the needs of the ICT ind ustry and, on the other hand, to keep our clients (learners, parents, the public and other stakeholders) informed about our instructional offerings addressing these needs.

The article covers background information on the discipline of Informing Science, the nature of the ICT industry and the importance of a higher education/industry partnership in preparing learners for a career in the ICT industry. This is followed by a description of the research process aimed at improving information flow.

\section{Background}

\section{Informing Science}

Informing Science is an emerging discipline for investigating the provision of the right information at the right time to the right clients. Cohen (1999) describes the term Informing Science as applicable to "disparate fields that share the common goal of providing a client with information in a form, format and schedule that maximizes its effectiveness". Information has been defined as "that which reduces risk for the decision-maker". It is important to realise that the 'information technologies' that are used to transfer the information - or create information from data - are not limited to computing, as is sometimes implied in discussions on the 'informing science' discipline. A simple 'manual' process aimed at keeping clients informed about the activities of an organisation, also belongs to the field of Informing Science. While an Information Systems function in an organisation is to provide managers and other business clients with information, other fields may define their clients differently. For example, the clientele for higher education institutions include learners, business and industry.

Cohen (1999) describes the Informing Science Framework as consisting of three components:

- The informing environment

"To provide information to the client in a form, level of detail and sequence to optimise the client's ability to benefit from that information."

- The delivery system

This refers to the use of "information technologies" for the implementation of the informing environments. 'Information technologies' in this sense is not limited to computing.

- The task-completing system

The task defines what information is needed and the task completion involves a person who has to make a decision. This element differs for the various academic disciplines (such as business, library science and education) that comprise Information Science.

\section{The Changing Role of IT Employees in Organisations}

Literature produced by research projects worldwide is unanimous in saying that organisations have undergone significant changes over the past several decades and that very few professions have seen as rapid a change as those in the field of Information Systems and Information Technology (Lee et al, 1995; Benamati,1998; Harvey,1997). Advances in technology and business methods have changed the 
ways in which companies operate. The modern ICT sector is fast-paced, tough and competitive and the range of knowledge and skills that must be available to a company has expanded and diversified. Today, employers are looking for potential employees who display a combination of knowledge, skills and attributes like agility, innovation and leadership. Along with a solid skills- and academic base, a willingness to learn on the job and to upgrade skills are important. Innovation is vital in the ICT environment and people should be looking at old problems in new ways. This brought about a new set of problematic issues for the ICT industry, where a new type of employee with a different profile of knowledge, skills and attributes is needed.

An important trend in research on the skills requirements of IT employees is an increasing emphasis upon interpersonal skills and the ability to communicate with others who are involved in the information systems development process. IT professionals need more than technical skills, as technologies are changing quickly and many of these technical skills are soon obsolete.

\section{Choosing a Career}

Choosing a career is one of the most important decisions one has to take early in one's life. Many people do not like their jobs and considering that one will spend more waking hours at work than at any other activity, this phenomenon is very disturbing. People end up in the 'wrong' jobs, because they are not true to themselves and follow a career path by doing what friends or family tell them. They accept the first thing that comes along, or they look at a series of occupations and guess which one would suit them best. Today, more than ever, knowing one's own strengths, weaknesses, preferences, skills, interests, values and personality type is critical in taking control of one's career.

The career path of the successful IT worker is currently very topical and seems to be different from five years ago. In the past the typical career path of an ICT professional was linear - from programmer to systems analyst to project manager to ICT manager. In a sense the lower level ICT jobs are rapidly disappearing and the requirements for ICT professionals are becoming more demanding in multiple dimensions, particularly in the areas of business functional knowledge, interpersonal- and management skills. It is crucial for learners to be informed about the different career options in the ICT field and that they base their career choice upon this information.

\section{The Role of Higher Education}

Higher Education, in terms of both quantity and quality of skills at all levels, is the "prime determinant of a country's level of industrial productivity and hence competitiveness" (Harvey, 1998). For South Africa to play a role in the world of technology and computing, it would therefore be essential that academic institutions produce technologically literate young people - with the necessary business, social and communicative skills - and provide the capable workforce that the country needs. In the climate of change, graduates in South Africa have to be aware of the changing nature of jobs and the required profile of employees in the different fields of ICT.

According to Hillman (1999) the total quality management (TQM) philosophy is spreading to higher education institutions. The fundamental purpose of TQM is to serve the clients better and "academic institutions serve several clients, including learners, employers, parents, alumni, lecturers, taxpayers, supporters, governing boards, administrators, staff, research users and society as a whole". Some of our most important customers are the firms that hire the institution's graduates. We must therefore have the resources and be flexible enough to serve the various needs of our client s. Within the TQM framework, our academic managers and lecturers should aim to understand the needs of the industry and the learner after graduation and "transform" it into improved training programs. 


\section{Higher Education/ICT Industry Cooperation}

The ICT indus try in South Africa is a complex one and companies can no longer deny their reliance on and social and economic responsibility toward higher education institutions in the country. The industrial sector has, for a long time, been the reluctant partner in the drive for industry-higher education cooperation. Probably because of uncertainty in the ICT industry and the need to reach out to new sources of ideas, many firms are now contacting us and are showing their willingness to investigate and build collaborative relationships with us. The creation of effective joint programs of curriculum design, lecturing, research, and the investment of funds in the activities of the academic institution can result from such cooperation. The foundation can be laid for a formal partnership program between our higher education institution and the ICT companies in close proximity to us.

It has been shown that the presence of successful businesses in a community is important to the economic health and stability of the community. Education and training are critical components in building corporate strength, leading to more jobs. Sims (1989) found that "not only workers, but industry too, is increasingly turning to institutions of higher education for new knowledge and new skills. Serving this new clientele has led to an increase in the number of industry/college training partnerships and, in turn, a mutual attempt to address industry's training needs." This was also found to be true for our institution, hence a greater focus on the link with industry.

\section{The Needs Analysis Process}

\section{The Higher Education/Industry "Expectation Gap"}

Academic institutions throughout the world have often been criticised for delivering a product to the industry that is not fit for purpose (Trauth, 1993; Mawhinney, 1995; Mawhinney, 1999; James, 1992). Often, industry is not asked what should be included in the ICT curriculum and higher education can be faulted for teaching "obsolete technologies" and "irrelevant programming languages." Trauth et al (1993) refers to an "expectation gap" resulting in companies having to retrain graduates from higher education institutions. To close the gap between the expectations of the ICT industry and what higher education delivers, Trauth suggests that industry and tertiary educational institutions must work together and that companies need to send consistent messages to universities and technikons about their expectations.

\section{Advisory Boards and the Need for Formal Research}

Advisory boards comprise respected industry representatives, who have practical experience in the relevant area(s) of the ICT field. Meetings are held three to four times per year to discuss the course structure and contents and determine its relevance. Where needed, new products and methodologies are introduced into the course contents, often with the help of the committee members.

Previously, many of the changes to instructional offerings at our institution have been based on the opinions of the advisory committees and academic staff. Despite the valuable feedback from the advisory board members, they do not represent the entire spectrum of companies with an ICT focus and they sometimes tend to give a one-sided view of the real needs of the total ICT industry. Our institution believes that, to effectively manage the academic programs, we must also have access to alternative sources of information to verify that the points of view exposed by the advisory committee represent reliable data on which to make changes or plan courses of action. It is thus necessary to do an in-depth investigation (formal research) into the needs of a representative number of ICT companies and to create and maintain close links with the ICT industry. We have no doubt that the days of the "take what you get" approach are counted. 
Research is therefore continually needed on a wider scale. Furthermore, conducting personal interviews with participants will alleviate many practical problems of scheduling advisory committee meetings to suit everybody. As a higher education institution we decided to initiate a project to continually and systematically examine the fit between the skills and knowledge possessed by ICT graduates and the requirements of the ICT industry. When we do research on the required profile of ICT workers, the following aspects of the profile are addressed (Cheney et al, 1990).

- Knowledge refers to the content of technical information needed to perform adequately in a job and is normally obtained through formal education, on-the-job training and information media such as manuals.

- Skills are the specific psychomotor processes necessary to meet the current requirements of a specific job. They are manifested through behaviours such as conducting an effective interview, writing a well-structured COBOL program, or developing a structured system specification.

- Abilities refer to the cognitive factors representing present capabilities or achievement levels.

It is our responsibility, as an educational institution, to "extract" this information from the industry, rather than expecting industry to "feed" us the information. The purpose of the research process is to follow a formal procedure to determine what is expected of the IT worker and then adapt our programs to address the necessary skills, knowledge and attributes. To understand how the profession of the IT worker has changed, we analyse the changing technologies, the changing business environment and the changing role of ICT in organisations - all factors driving the change in the profile of the ICT worker. This information is then conveyed back to the learners, their parents, employees and other stakeholders.

\section{The Research Process}

\section{First phase}

To determine the needs of the ICT industry in our region, a formal research process was done at our institution during late 1999 and 2000. The chosen methodology was action research, which would have been impossible without the active involvement and commitment of our academic staff and the ICT industry in our region. A clear picture of the ideal ICT worker - consisting of the technical and nontechnical knowledge and skills, as well as the personal attributes of the ICT worker in various areas of the ICT industry, was obtained through a formal 'needs-analysis program'. Major issues, as faced by ICT professionals were also determined. To ensure the relevance of ICT training, industry requirements were then related to the academic preparation of future ICT professionals.

An extensive literature study was done on the international ICT industry and the ways in which other tertiary ICT training institutions address their problems. The non-technical skills and personal attributes required of IT employees were also investigated and used as a basis for further investigation. In the survey phase, qualitative and quantitative information was obtained through the use of structured questionnaires, as well as personal interviews with senior- and line managers in the ICT industry. The questionnaires were distributed and completed on the Internet. From the questionnaires information was obtained on the various areas of specialisation in the ICT field, the non-technical skills required and the problems experienced by employees in the ICT field. Personal interviews were conducted to obtain supporting information on the issues covered by the questionnaire. The advantage of following up the questionnaires with personal interviews was twofold: Firstly, the industry representatives could be quoted in relevant situations, to convince learners of the importance of certain changes to the courses. Learners often do not believe their lecturers that non-technical skills and abilities are important in the world of computing, and they therefore resist modules focusing on communication- and interpersonal skills, personal development and teamwork. Secondly, the method of personal contact through interviews was deliberately chosen to acquaint members from the ICT industry with the activities of our institution, and to 
investigate the possibility of creating partnerships between the company and the institution. Through the project we also aimed to improve the method of information retrieval for follow-up research projects of a similar nature. The feedback from the participants and the experiences of the researchers were used to improve the methods for similar future projects.

The research involved companies with ICT activities in Gauteng, South Africa. Potential employers of our learners were selected for the study, as well as members of the Advisory Committees, employers of our learners for the Industry Exposure period, hardware- and software suppliers and donors. The participants in the interviews were all leaders in the ICT field, who play strategic roles within their companies. Typically, the senior manager (probably the IT manager) and one or more line managers working in the company were incorporated in the interviews. A total of 23 IT managers completed and returned the questionnaire and personal interviews were conducted with a total of 30 managers.

This research project aimed to serve as a guiding project to test the methods of obtaining the necessary information from the industry, including personal interviews with ICT managers and completion of the questionnaire directly via the Internet. An important outcome of the research was an awareness of the importance of doing regular needs analysis projects in industry, probably every second year. The marketing value and the "personal touch" of conducting interviews should also not be underestimated. This project was an important first step in "putting us on the map" and informing the ICT industry of our activities.

In summary, higher education institutions need information from local business about the needs of the ICT industry, for the following reasons:

- The ICT curriculum can be re-engineered to meet the current needs of local industry

- Better curriculum and career advice could be provided to ICT learners

- The marketing of the ICT instructional offerings to prospective learners can be improved

- Closer contact with the local business community can be established.

\section{Results of the first phase - new course structures and contents}

During the research it became clear that the three or four years spent at an academic institution was not enough to teach learners enough about all the areas of the ICT field. Industry representatives suggested that our learners should start specialising during their diploma or degree program. The research also confirmed the importance of in-depth teaching and hands-on experience. The focus areas and contents of such specialisation degrees were also discussed and eleven possible specialisation areas were ident ified. Five of these fields received $86 \%$ of the total number of votes and were therefore clearly more important than the others. After completing this part of the research, our entire course structure was redesigned and four of these specialisation degrees are currently presented at our institution:

Business Applications. The business applications specialist field was supported very strongly. This course covers the creation and customisation of effective IT solutions to business problems and the management of those systems. The course comprises a thorough business education, as well as a solid IT background and a personal development focus. Typical career options for these learners are business analysis, systems analysis and project management. The training therefore takes the business analyst role beyond the ability to define business requirements and translate it into systems terms, but also teaches the learners how to quantify business benefit and be able to look for continuous improvement.

Software Development. Learners learn to design and produce software products and systems to meet specified needs so that they work reliably and their production and maintenance is cost-effective. An overwhelming majority of the participants regarded programming as an essential skill, regardless of the area of the ICT industry where the person works. 
Communication Networks. Learners examine issues involved in the design, implementation and management of local area networks and their interconnections locally and through wide area networks.

Web Applications and -development. The fast rate at which the Internet has been introduced to the world of work, has necessitated the separation of a career in web page design, web application development and webmaster.

The project had a drastic impact on the training programs offered by the department, as well as the future strategies and structure of the Department. Many changes and improvements were made to the teaching programs. For instance, the first year of study is the same for all ICT learners, followed by specialised training in further study years. Industry exposure and professional development remains an important part of the new course structure. Although our traditional role was to provide a new supply of learners with technical skills to the labour market, we are now also involved with professional training, to broaden or update their education to include non-technical skills. The non-technical skills and personal attributes required of ICT employees (and therefore learners) were also determined during the research project and subsequently included in the training programs. Changes to the courses have been finalised and implemented during 2001.

\section{Follow-up research (phase two)}

The purpose of the Business Applications department is to produce employees with strong IT-, businessand people skills, to bridge the gap between business and the IS/IT function. Literature refers to an "adverse relationship" and lack of "fusion" between business and IS/IT, necessitating a strong focus on analysis and interpersonal relationship skills. The next phase of the research process is currently being done to investigate the reasons for the lack of fusion between business and IT. The role of the analyst in creating fusion through requirements analysis and interpersonal relationship management, are investigated in depth. The industry perceptions of the roles and responsibilities of business- and sys tems analysts is determined and translated into industry needs and career options within the specialisation field of Business Applications. This part of the research therefore focuses on the specific skills, knowledge and attributes required of such learners and this profile will be updated from time to time and used as a basis for the four year BTech IT (Business Applications) degree course. The results of the research will assist learners in making informed career choices and are therefore shared with prospective and current learners. The process will have to be repeated for all the other specialization fields at a later stage, based on lessons learnt from this project.

Content analysis. Available literature and discussions with prominent professionals in the ICT industry indicated that job titles and job descriptions in this field are by no means a clear-cut case, and the names Business Analyst, Systems Analyst and Business Systems Analyst are used interchangeably. Furthermore, titles such as relationship manager, business architect, client service manager and requirements engineer are also used to refer to this role.

Content analysis of a sample of job advertisements and position descriptions of, business analysts, systems analysts and business systems analysts is done to provide baseline information about the required profile for these positions. Relevant key words and key sentences that describe the roles and responsibilities are collected from each entry, showing important aspects of the position. The importance of an idea is revealed in the frequency with which it appears in the text.

The required attributes and abilities of these employees are determined with reference to their

- role and responsibilities

- technical (ICT) knowledge and skills

- non-technical knowledge and skills

- personal attributes 
The primary data consist of Internet job advertisements, newspaper job advertisements, instructional offerings at higher education institutions throughout the world and journal articles. Secondary data are derived from personal interviews with IT managers, practicing business- and systems analysts, relationship managers and recruitment specialists.

Personal interviews. Personal interview sessions and focus group meetings are held with business- and systems analysts in the Gauteng region of South Africa, to determine their roles and responsibilities. Both open - and closed questions are used during the interviews. The information obtained is added to the results from the content analysis. Included in the interviews are questions on the

- organisational behaviour issues faced by business systems analysts

- soft skills required of business systems analysts when having to cope with these "people issues"

\section{Preliminary results of the second phase research}

The comments made by people from the ICT industry are very valuable to learners wanting to enter into a career as an analyst in the ICT field. These comments are communicated to learners, thereby giving them a clear picture of the career path and job requirements of the different positions in this area. As a result of the research, the role of the combination of business- and systems analyst is described to the learners as follows:

"One of the most fundamental and challenging information technology positions is that of the analyst. These analysts are responsible for analysing business needs through careful study of business processes and communications with customers. Once the analysis is completed, the analyst must communicate the results to the programmers who will code and implement the solution. An analyst liases with the programmers and customers throughout the entire development and installation process. The analyst is key to ensuring a good fit between the information system and the organisation. His/her role is integral to the success of the information system and, in turn, the success of the organisation. The most important skills required of an analyst are customer interaction, needs assessment and prioritisation. The combination of these skills magnifies the importance of the business systems analyst's liaison role between the technical and non-technical aspects of the organization. He/she should have interpersonal skills and the ability to analyse and anticipate the information system needs of the organization."

Examples of valuable comments made regarding the world of the business systems analysis and relationship management, are included in appendix 1.

\section{Benefits of the Needs Analysis Program}

Research to determine the profile of the ICT industry and ICT professionals benefit our academic institution in many ways. It enables us to present up to date instructional offerings and, because the best and most recent information is available to the academic staff their lecturing abilities improve. Close contact with industry leads to mutual understanding, -support and valuable partnerships with the possibility of cooperative research between industry, lecturers and learners. Placement of learners in industry, with the purpose of gaining industry exposure, is facilitated. This process is simplified when a trust relationship exists between industry and higher education.

\section{Limitations of the Research Process}

ICT personnel (especially managers) have very limited time to spend on surveys. This causes delays in establishing contact and setting up meetings with participants. Due to the large number of ICT related industries and the time and distance restriction, only companies in the Gauteng region of South Africa are included in the study. The methods used for collecting employer views are potentially problematic, especially an Internet-based questionnaire - valuable input could be lost due to unreliable network con- 
nections. Responding to employer views may raise issues of academic freedom and doubts about the rounded educational development of the learner. Many academic practitioners are concerned that employers may have short- term views and disregard longer-term economic or educational strategy. One of the major problems facing many higher education institutions in South Africa is the delay between the design and implementation of curriculum changes. New qualification proposals have to be circulated to other higher education institutions, to ensure that all inputs have been gathered. This is a very timeconsuming exercise.

\section{Information Flow from the Higher Education Institution to the Learner}

\section{Type of information}

The type of information needed by learners to make an informed career choice is typically the following:

- The state of the ICT industry - now and in the future

- Careers in the ICT industry - now and in future (important quotes form industry)

- Training options (e.g. certificate, diploma, degree)

- How to apply for the study period - which forms to complete, the need to write an aptitude test and other logistic information

- What are the requirements for entry into the different instructional offerings

(e.g. Mathematics as a school subject)

- Subjects / topics covered in courses

- Industries and companies where learners can work after graduation

- Requirements of the job - technical knowledge, non-technical knowledge and personal attributes.

- With whom will they work (e.g. accountants, engineers, economists)

\section{Methods for informing clients}

Academic institutions use various "vehicles" to transfer the information to the client. Open days are held where all the courses offered by the institution are explained to the public. The disadvantage of such an open day is that prospective learners receive an overload of information on various fields of study and focused advice on ICT can seldom be given. Road shows are organised at schools in the region of the institution. Prospective learners and their parents are informed about the career possibilities within the ICT industry and the heads of the various specialisation areas give advice on relevant matters concerning the different options. The presentation should obviously contain updated information.

The specialisation areas and career options are covered in the study material of one of the first year modules. Hereby learners are forced to "study" and understand the differences between the focus areas. Learners have to complete an assignment on the career options in the different specialisation areas. Before learners finally select a specialisation area, the head of each department does a short presentation to first year learners. Academic staff must ensure that they base their choice of a career on the correct information and for the right reasons (not only for short term benefits such as initially earning high salaries).

Radio interviews, for informing prospective learners and companies about the training opportunities, and information sessions at companies in the region are also conducted. ICT managers, supervisors and human resource practitioners are invited to these sessions. 


\section{Conclusion}

Being informed about the characteristics of the ICT industry and the career options within this industry is an important factor in making the right decision. What then, is the role of academic staff at higher education institutions when informing the clients about the options?

In the context of the higher education/industry relationship faculty should be involved in determining what changes have taken place in organisations and the ICT industry in particular. They should determine the various career options in the industry and the characteristics of each (e.g. job description, compensation, etc.). The required profile of these specialisation areas should be investigated and course structures and module contents should be designed accordingly. Prospective and current learners (as well as other stakeholders) should be informed through various means.

Higher Education should therefore continuously determine the profile of skills and knowledge in order to adapt its structure and programs to the changing needs of the industry. They should continually be looking for better ways to meet the growing demands of an increasingly diverse learner population and strive to offer training that meets the needs of the ICT industry, includes the latest technology as part of the courses and gives the learner a broad enough base not to be stranded when product technology changes drastically. Learners should be enabled to grow toward whole, mature human beings who are productive immediately after completing the degree/diploma and who can learn and quickly adapt to new circumstances and new technology.

This can only be done with the involvement of industry in stating their needs and becoming involved in various activities of the higher education institution. Higher education institutions should attempt to involve employers on a partnership basis at all stages of course development and monitoring, instead of seeking post hoc reactions to course provision. Learners and other stakeholders should be informed of the results of industry liaison.

A model showing the type- and flow of information in the practical application of Information Science in ICT Education (the ISIE model) is included as appendix 2.

\section{References}

Benamati, J., \& Lederer, A.L. (1999). An Empirical Study of ICT Management and Rapid ICT Change. ACM SIGCPR, 144 $-153$.

Benamati, S. \& Lederer, A.L. (1998). Coping with Rapid Change in Information Technology. ACM SIGCPR.

Cheney,P.H. et al. (1990). Knowledge, skills and abilities of information system professionals: past, present and future. Information and Management, 19, 237-247.

Cohen, E. (1999). Reconceptualising Information Systems as a field of the Transdicipline Information Science : From Ugly Duckling to Swan. Journal of Computing and Information Technology, 213-219.

Gregory, Eugene H. (1997). University-industry strategic partnerships. Industry \& Higher education, 253-254.

Harvey, L \& Green, D. (1992) .Employer satisfaction. QHE: Birmingham.

Harvey, L., Moon, S \& Geall,V. (1998). Work Experience: Expanding opportunities for undergraduates. Centre for Research into Quality : UCE, Birmingham.

Harvey, L, Moon, S \& Geall, V. (1997). Graduates' Work: Organisational change and students' attributes. Centre for Research into Quality : UCE, Birmingham.

Hillman, T. \& Taylor, A.J. (1999). Total Quality Management and Higher Education: The Employers Perspective. Total Quality Management, 10, 7, 997.

Hughey, A.W. (1997). What higher education can learn from business and industry. Industry \& Higher education, 73-78.

James, M.L. (1992). Are we Teaching what Employers want? Business education Forum. 8-10.

Kelly, John. (1996). University-industry partnership in the curriculum Industry \& Higher education. 
Lee, D, Trauth, E.M \& Farwell, D. (1995). Critical skills and knowledge requirements of IS professionals: A joint academic/industry investigation. MIS Quarterly.

Mawhinney, CH et al. (1995). Updating the IS curriculum: Student perceptions of industry needs. ACM SIGCPR. Extended abstract.

Mawhinney, J.S. et al. (1999). Updating the IS Curriculum: Faculty Perceptions of Industry Needs. ACM SIGCPR. 219 221.

Skilbeck, M \& Connell, H. (1996). Industry-university partnerships in the curriculum: Trends and developments in OECD countries. Industry and Higher Education, 9-22.

Sims, R,R. \& Serbenia, J. (1989). American Colleges and Training for Industry. Industrial \& Commercial Training, 21, 6, 36.

Trauth E.M. (1999). Who Owns my Soul? The Paradox of Pursuing Organisational Knowledge in a Work Culture of Individualism. ACM SIGCPR, 159-163.

Trauth,E. et al. (1993). The IS expectations gap: Industry expectations versus academic preparation. MIS Quarterly.

\section{Appendix 1}

\section{Comments Made by Interview Participants}

"Business analysts need to have a sense of what it takes to run a successful business. Profitability is important and you should know what it means to increase revenues and manage costs. Training in management accounting and activity based costing is desirable."

"Business problems do not come as neatly packaged as marketing problems, accounting problems or organizational problems. They arise within the context of the business, with all the complexity and richness that a business provides."

"You'll be working in cross-functional teams, involved in building consensus and making management decisions. You should be a good communicator and a team player. Training in communication and negotiation skills is desired."

"You will need to work with computer scientists, management scientists, information systems analysts, database specialists and administrators, economists, statisticians, accountants, financial managers, financial analysts and market analysts."

"You will need to understand your customers and the markets. Research design and analysis skills are critical - e.g. conducting market research studies, using database- and statistical packages. Training in measurement and statistics is desirable."

"Business analysts should be focused on influencing business decisions that impact the sales forecast. They will determine where the inefficiencies are and make recommendations to improve the profitability of the business."

"Learners must realize the importance of deadlines."

"Learners should see how important effective communications are to both team and client relationships."

"Frequent changes in technology will test the adaptability of learners."

"Mastering new languages, new software and hardware should be a continuous challenge." 


\section{Appendix 2}

\section{Information Science for ICT Education (ISIE Model)}

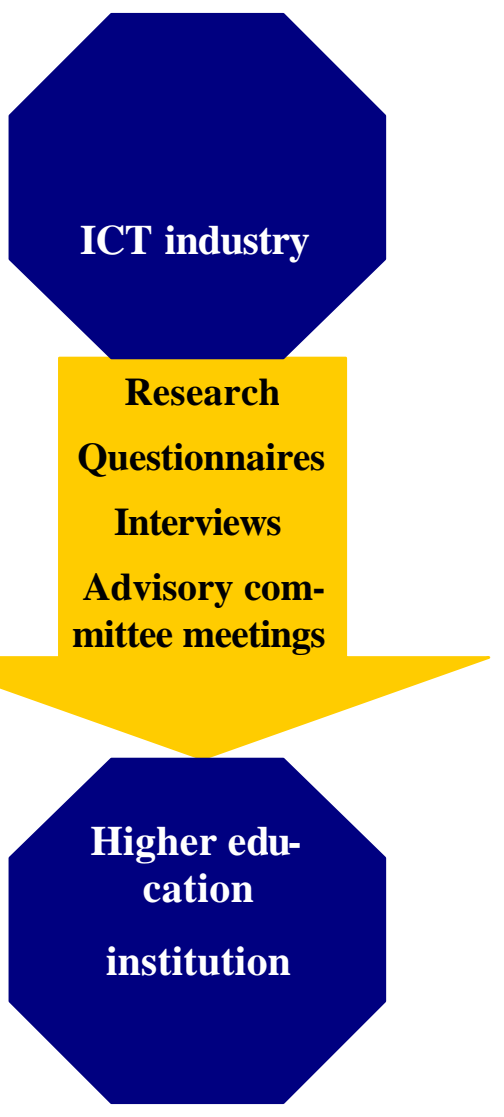

\section{Information}

The state of the ICT industry - now and in the future

Careers in the ICT industry - now and in future

Requirements of the job - technical knowledge, non-technical knowledge, personal, attributes,

With whom would you work (e.g. accountants, engineers, economists)

Industries and companies where you can work after graduation

\section{Information}

\section{Open days}

Road shows at schools

Information in the study material

Presentation by department head Radio interviews Information ses-

Training options (e.g. certificate, diploma, degree)

How to apply for the study period which forms to complete, the need to write an aptitude test and other logistic information

What are the requirements for entry into the different instructional offerings (e.g. Mathematics as a school subject)

Learner

Parent

Employee

Teacher 


\section{Biography}

Mrs Evans joined the department of Computer Technology at Technikon Pretoria as a lecturer in 1988 after obtaining a degree in Computer Science and a Higher Education Diploma (HED). She lectured in many aspects of computing, including programming $(\mathrm{C}, \mathrm{C}++$ and Delphi), systems software and operating systems. During this time she completed the BSc(Hons)(Computer Science) degree. In 1995 she became the section head responsible for industry liaison, where the importance of strong links between academic institutions and the industry was highlighted. In 1997 she was appointed Head of the Department of Computer Technology, the largest and fastest-growing department in the Technikon. In this position she was responsible for the general management of the department, consisting of five academic sections with 50 academic staff members and four permanent administrative staff members. The infrastructure and facilities consist of more than five computer laboratories with 400 computers. For her research on the profile of the Knowledge and Information Technology worker she received the MTech Information Technology degree from Technikon Pretoria in 2000.

In January 2000 she was awarded a bursary by the former president of South Africa, Mr Nelson Mandela for Masters level study at an Australian university. She chose to enrol for an MBA(IT) degree at Bond University and completed the degree in September 2001. Since then she is responsible for designing and implementing the detailed course structure for the specialisation qualification BTech IT(Business Applications) at Technikon Pretoria. She currently manages the academic programs and personnel of the department responsible for this qualification and lectures fourth year subjects in Business Management, Business Fundamentals, Information and Technology Management and Strategic Information Systems. In January 2002 she enrolled for a PhD degree in Organisational Behaviour at the University of Pretoria. The coursework consists of Research Methodology, International Management and Organisational Development, focusing on individual behaviour, group/team behaviour and organisational structures. She aims to complete this qualification by the end of 2003 with a dissertation on the creation of business-IT fusion and the role of the analyst in bridging the "expectations gap" through proper needs analysis and interpersonal relationship management. 